\title{
How price moderates assessments of coffee quality across profiles of gender and experience
}

\author{
D. Priilaid* and B. Horwitz \\ School of Management Studies, University of Cape Town, Private Bag, Rondebosch 7700, South Africa \\ *To whom all correspondence should be addressed \\ david.priilaid@uct.ac.za
}

\begin{abstract}
Proceeding from studies that identify the extrinsic price cue as a mediator between a product's perceived and intrinsic merit, we report on a blind-versus-sighted coffee tasting experiment conducted to determine the impact of the price-cue across coffee-user categories of gender and relative experience. Seven instant coffees were tasted by 100 subjects producing 700 paired blind and sighted tastings. Aggregating the data, OLS regression models were run to estimate price-effects across discrete and overlapping bands of gender and self-confessed expertise (non-expert and expert). Our analysis reveals the extent to which price-effects demean a coffee's intrinsic merit during sighted tastings, with experienced male coffee drinkers most especially susceptible to price persuasion, and less experienced female drinkers the least. Thus our paper introduces a cheap and affective means of testing for such cue-effects. Neuromarketing styles of testing are usually cumbersome, expensive and difficult to scale. The method show-cased here offers a meaningful alternative. These findings uphold the view that the price cue remains a critical tool in the marketing of coffee; most notably because of its potential cost-free contribution to the ramping of experienced pleasure without any augmentation of quality. Further implications are explored.
\end{abstract}

\section{Introduction}

The process of automatic cognition is coded to steer us swiftly through familiar environments with minimal effort (Kahneman, 2012). Evolved over millennia, this neural system scans for interpretive contextual cues which serve as heuristic substitutes for more complex underlying phenomena. A primitive example could be that of a snapping twig signalling the approach of a predator. Those early humans instinctively responding to this cue were more likely to pass on their genes. Those preferring the slower and riskier alternative of first exploring the source of the snap were more likely to die (Montague, 2006). Governed by imperatives of survival and procreation faster cue-based judgements served critical prehistorical purposes; their strategic import mitigating the potential inconvenience of any detection-error to which automatic cognition is inevitably prone (Berridge \& Aldridge, 2008).

With automatic cognition still a part of Homo consumericus (Saad, 2013), this paper follows the recent injunction to examine pricing as a component of neuro-marketing research (Lee, Broderick \& Chamberlain, 2007). So doing we explore cue-driven detection errors as a contemporary driver of consumer behaviour. Here we employ the price-quality heuristic as the source of such error, noting that shoppers will employ price as a proxy for quality, particularly when direct sampling of a product's intrinsic merit is not possible, as is the case of coffee (Chao \& Schor, 1988; Erikson \& Johansson, 1985; Lichtenstein \& Burton, 1989, Olsen, 1977; Stafford \& Enis, 1969; and Zeithaml, 1988). The use of the price cue is significant since it has been observed to increase the level of experienced pleasantness without actual product augmentation; the magnitude of the price point typically corresponding with the scale of error provoked (Plassmann, O’Doherty, Shiv \& Rangel, 2008).

Notwithstanding the more recent literature on the pricequality heuristic and the associated manifestation of nonmedical placebo effects (see the special 2005 edition of the Journal of Marketing Research, especially Shiv, Carmon \& Ariely, 2005, and the special 2012 edition of the Journal of Consumer Psychology, especially Plassmann, Ramsøy \& Milosavljevic, 2012), few studies have considered how the price-quality heuristic is acquired, within which demographic segmentations the heuristic is most prevalent, and why. Proceeding thus, we note that cues relating to reproduction and survival are genetically encoded. Thus our responses to spiders, snakes, or even a woman's hip-to-waist ratio are instinctual; not learnt (Saad, 2013). This is not the case with the price-cue which we learn to correlate with quality through our neurological predisposition towards heuristic deployment (Solnais, Andreau-Perez, Sánchez-Fernández \& AndréuAbela, 2013). Recent studies by Priilaid, Sevenoaks, Aitken and Chisholm, (2013) and Priilaid and van Rensburg (2016) explored this dynamic using wine and cheese tasting experiments to examine how the sighted tastings of certain user profiles were influenced by the presence of price information. No other price-related research, either generic or specifically focussed on coffee (regular or instant), appears to exist on this topic.

This piece follows on from these studies to examine (1) whether increasing product expertise provokes a greater propensity for intuitive price errors and (2) how the scale of 
any such errors might manifest differentially across combined samplings of gender and expertise.

We proceed to note that coffee evaluations may be conducted either sighted or blind. By definition, blind tastings carry no extrinsic cues and are hence void of external bias. Controlling for blind ratings, the mediating effect of the extrinsic price cue may thus be captured and quantified in any subsequent sighted coffee assessments. (For the blind tasting the individual must rely on actual intrinsic properties in making their quality assessment, while in the sighted tasting, the individual relies on both intrinsic properties and price).

In this study we report on a tasting room experiment where 100 subjects assessed seven coffees first blind (round one) and then sighted (round two). A pre-specified randomized tasting sequence was employed in each of the blind and sighted rounds, with the price point of each of the seven instant coffees being the only cue information available in the second "sighted" round. Across the seven coffee sample, prices points (per 200g) ranged between the cheap (R18) to relatively expensive (R90). Pooling the seven ratings of each of the 100 subjects, a dataset of 700 paired blind and sighted coffee assessments was thus collated to determine the degree to which price-errors could be identified, quantified and interpreted across discrete and overlapping segmentations of expertise and gender. Unlike the more expensive technological methods of neuro-marketing enquiry such as positron emission tomography (PET), galvanic skin response (GSR), and functional magnetic resonance imaging (fMRI) (Lee et al., 2007), with appropriate controls, we posit that the blind-to-sighted tests as applied in this research provide a fast, scalable and cost effective means to understand how consumers process marketing cues such as price. We showcase this method here to introduce readers to this means of analysis.

Following this introduction, we present a brief review of the literature. In Section Three thereafter follows the experimental design and dataset; proceeded in Section Four by a series of regression models contrasting the differing price effects. Section Five concludes.

\section{Literature review}

When consumers have a greater knowledge about product classes they tend to make generalizations about the product as well as about the quality associated with that particular class (Pecotich \& Ward, 2010). This is especially so in purchase situations where customers are faced with an assortment of products, each with their own unique set of quality-connoting attributes. To the would-be customer, such assortments present the cognitively daunting challenge of knowing what product information to process and what to disregard (Rao, 2005). In information-rich shelf-front environments, there is evidence that consumers activate certain heuristic short-cuts that may save time evaluating new information (Cunha \& Shulman, 2010). One of the most common short cuts is the perceived price-quality heuristic, a construct well entrenched within the literature (Dodds \&
Monroe (1985), Gerstner (1985), Rao and Monroe (1988), Rao and Sieben (1992)).

Further studies have shown that an over-reliance on the pricequality heuristic may lead to an obscuration of a product's true merit. Tellis and Wernerfelt (1987) found a variety of positive correlations between objective quality and price, and cautioned consumers against an over-reliance on this relationship. A similar study by Priilaid (2006) showed how the marginal correspondence between sighted and blind wine assessments could be explained by the detrimental influence of the price cue on sighted scores, with such cues serving as a Pavlovian conditioning stimulus. Classical or Pavlovian conditioning occurs when two stimuli are paired such that affect is transferred from one stimulus to another. Such conditioning has been recognized as a significant mechanism in the genesis of hedonic preferences and hence ultimately the modification of behaviour (De Houwer, Thomas and Baeyens, 2001). This conditioning mechanism is entrenched within a dual system of mental processing: on the one hand is a conscious rational system based on verbal reasoning specific to humans; on the other is a non-conscious experience-driven system of associative learning common to both humans and animals (Epstein, 2010; Evans, 2008). Operating at what Simon (1992) calls a "symbolic" or abstract level of information processing, each of the dual systems run in conjunction to the other, acting out of often conflicting imperatives, such as the need for speed versus accuracy, depending on circumstances. Through the acquisition of experience, the intuitive fast acting thought system becomes primed to solicit heuristic-type cues aimed to enable efficient and rapid decision making and maximum reward utility (Berridge \& Aldridge, 2008). This associativeexperiential system is hedonically motivated and affect driven, tasked to achieve positive ends and avoid negative ones. It is believed to have been adopted over millennia by most animal forms including humans as a Darwinian strategy aimed at either survival, reproduction, kin selection or reciprocal altruism (Montague, 2006; Saad, 2013, Taleb, 2007). Observe here that unless the conditioned stimulus can be employed to predict the unconditioned one, an organism acquires no ecological benefit in learning an association between the two (Abrahamson, 1994).

Within this dual thought system the more rapid, older and reactive thought process has been described as "associative" (Smith \& DeCoster, 2000), "tacit" (Hogarth, 2001), "implicit" (Strack \& Deutch, 2004), and "peripheral" (Petty $\&$ Wegener, 1999); terms which are all character appropriate. Stanovich and West (2000), Kahneman (2003; 2012) and Morewedge and Kahneman (2010) have termed it "System 1"; labelling the slower, more deliberate and analytic thoughttwin "System 2". Presenting a defining framework of this dual-system and calling it Cognitive-Experiential Self Theory, or CEST, Epstein (2010) places the role of experience centrally within it, stating that the CEST is an "an experiential system because its primary function is to learn from experience" (Epstein, 2010, p. 298).

Experiential learning of this sort has been shown to be susceptible to systemic errors of judgement (see for example 
Kahneman, Slovic \& Tversky, 1982; Myers, 2002; Nisbett \& Ross, 1980; and Shermer, 1997), errors that in the medical and marketing literature have been interpreted as placeboeffects (Amanzio \& Benedetti, 1999; and Shiv et al., 2005, respectively). Employing the dual thought process framework, Morewedge and Kahneman (2010) ascribe such errors to both System 1 detection failures, and an inability of the logical System 2 to sense and correct any errors that may occur. Hence, under enduring levels of cue exposure, System 1 appears to develop superficial cue associations that over time become repeatedly endorsed by System 2. Through continual reinforcement, this dual reasoning process matures, in time becoming a generator of instinctual protocols of behaviour.

The System 1 and 2 learning styles appear somewhat different, with the deliberately rational thought process learning through a slower pattern of deductive reasoning, sifting through the correlates of sensation and reward as it goes. By contrast, the sight-based system learns through a combination of observational learning and operant and classical conditioning, these forms combining as an adaptive means to negotiate one's surroundings. In a corroborating study employing a blind-to-sighted sampling of colas, McClure, Li, Tomlin, Cypert, Montague and Montague (2004) reported neural responses correlating with brand choice. Tasted blind, Pepsi was generally preferred; tasted sighted, the majority preferred Coke; arguably because of its dominant market share. Here, critically, the two styles of tasting revealed differing levels of activity in different parts of the brain: the ventral putamen region being activated in blind tastes; the ventromedial prefrontal cortex in the sighted. These two regions serve different purposes. The former region is known to process hedonic sensation and reward, the latter serves as the locus of recall and judgement. Findings from the study implied a neurological idiosyncrasy: that when tasting sighted, instead of processing a judgement of intrinsic merit as it would under blind tasting conditions, the brain rather prefers the ease of employing familiar heuristic-type cues. The degree of experience and extent of cue familiarity is critical here, System 1's adaptive-style of learning believed to correlate with the intensity of formative cue-priming experiences (Dollard \& Millar (1950) and Hull (1943) as cited in Epstein $(2010,298)$. With sight-based System 1's stress on speedy (as opposed to meticulous) decision making, some heuristic judgement errors become inevitable. The occurrence of these cue-driven errors is now well documented within the literature on experimental psychology (Kahneman, 2012), the brain sciences (Plassmann, et al., 2008) and even wine (Almenberg \& Dreber, 2011). Within the literature on such placebo-type cognitive errors, four extrinsic cues are currently identified as mediators of a product's intrinsic merit; namely area-of-origin (Priilaid, 2007), expert ratings (Siegrist \& Cousin, 2009), brand

\footnotetext{
${ }^{1}$ The so-called selectivity hypothesis suggests that men rely more on System 1 heuristics to process information, while women will tend to make evaluations based on a more considered appraisal of the situation (see Meyers-Levy and Maheswaran, 1991, and Meyers-Levy and Sternthal, 1991) that is therefore likely to include both System 1 and System 2. Though this
}

(Venkatraman, Clithero, Fitzsimons \& Huettel, 2012), and price (Plassmann, et al., 2008). While price presents as the most significant of these four cue-effects (Rao \& Monroe, 1989), little is understood of how these price-driven judgement errors actually accrue, especially with respect to bands of gender and relative experience. Within the context of coffee consumption, it is this gap in our knowledge that forms the central focus of this paper.

Accordingly, within the domain of coffee consumption, three focus areas emerge, namely: (1) the general manifestation of a price-quality heuristic and, further, the dynamic of this heuristic across discrete and overlapping bands of (2) gender, and (3) expertise.

\section{Price-quality Heuristic}

At an unstratified level, in studies reported, inter-alia, by Shiv, et al. (2005) and Plassmann et al. (2008), price information has been observed to modify the reported quality of certain hedonic products; either increasing or reducing the subjective assessment of actual intrinsic quality as per the associated price cue. Controlling thus for intrinsic merit, a similar result is anticipated here, whereby price-errors are anticipated to manifest within the fitted meta-model of sighted coffee assessments.

$\left(H_{1}\right)$

\section{Expertise}

In recent tasting studies by Priilaid, et al. (2013) on wine, and Priilaid and van Rensburg (2016) on cheese, when sampling sighted, novices appeared less affected by price information than experts. Running similar tests on blind-based scores, Goldstein et al. (2008) also found that, while, novices preferred less expensive wines, experts remained priceneutral. In line with both these pieces, price-effects are likely to strengthen across strata of increasing relative expertise.

$\left(\mathrm{H}_{2}\right)$

\section{Gender}

Adults will display a variety of sexual cues to flag their value as potential mates to the opposite sex, and conspicuous forms of consumption are rooted in this type of behaviour (Saad, 2013). The driving of certain luxury cars will, for example, yield increased levels of testosterone in men (Saad \& Vongas, 2009). Similarly, women are more likely to recall expensive status related products when in the fertile peak of their ovulatory cycle (Lens, Driesman, Pandelaere \& Janssens, 2012). This being so, do women and men display similar or differing degrees of price affect? ${ }^{1}$

In their sighted wine tasting study, Almenberg and Dreber (2011) reported that gender plays an important part role on how we respond to price information, with women

theory has found limited empirical support, and does not specify the evolutionary domains in which it might be applicable, (reproduction, survival, kin selection, etc.,) it does suggest that men might be more price affective than women. 
considerably more influenced by price than men, Priilaid et al. (2013) reported a similar result, with price effects 24 percent stronger across female strata, relative to males. The implicit inference therefore is that gender should play a determining role in sighted assessments of quality, with men less influenced than women. Accordingly, this study expects price-errors to manifest more strongly within female segmentations.

$\left(H_{3}\right)$.

\section{Data description and experimental design}

\section{Data description}

In this analysis 100 subjects were invited to a two-stage blindto-sighted coffee tasting. No payment was offered. The experiment followed a causal two-stage pre-experimental design format (Malhotra, 2010, 158), wherein the aim was to examine a potential cause-and-effect relationship between the price-cue and experienced sighted pleasantness.

In the first stage eight instant coffees were sampled blind one after the other with the only information offered to each participant being the nature of the product: i.e.: instant coffee. The blind sequence of tasting was random and did not follow by order of price. Following on from the blind round, to dissuade each subject from guessing the line-up of the second sighted round, one of the eight coffees tasted blind was removed, and the order of the remaining seven coffees to be sampled sighted (again one after the other) was reshuffled. In effect, and as applied to each of the 100 subjects involved, this procedure created a dataset of seven coffees sampled first as a sequence of blind tastings, and then as a new sequence of sighted tastings. This process thus created $700(100 \times 7)$ paired blind and sighted coffee tastings.

The testing process took place across five different groupings comprising twenty subjects in each $(5 \times 20=100)$. Critically, as per the tasting protocol of Lee, Frederick and Ariely (2006), each coffee was sampled sighted after the price cue had been revealed. Care was taken to ensure that key variables remained constant across each tasting session. Hence, along with the time of day, throughout the experimental process each coffee preparation remained the same: $500 \mathrm{ml}$ of hot (though not boiling) water, three teaspoons of coffee, one teaspoon of sugar, and $125 \mathrm{ml}$ (half a cup) of full-cream milk.

By order of price-per $200 \mathrm{~g}$, the seven instant coffee products sampled both blind and sighted were R18,00, R20,00, R22,00, R54,00, R57,00, R60,00, R70,00 and R90,00. Before the start of round one, respondents were requested to provide details regarding (a) their gender, (b) whether they considered themselves experts or non-experts, and (c) their age.

Each round of tasting was scored using a self-reporting eleven point Likert scale equivalent to the "five star" quality metric, with half-star calibrations, ranging between zero ("worst possible") and five ("best possible"). A five star score would indicate that the respondent rated the coffee as a world class product of exceptional distinction. Conversely, a zero would indicate that their experienced pleasantness was very low and that under normal conditions they would not choose to sample the coffee.

Aggregating demographic information from 100 selfadministered questionnaires and the seven coffees scored blind and sighted by each participant, a dataset of 700 (7 X 100) coffee assessments was compiled.

By omitting sighted cues relating to issues of brand, area-oforigin, caffeine content and retailer, and with first round blind tastes accounted for and therefore controllable in the second, no additional second round controls were required. Controlling both for intrinsic merit as measured in the first blind round and for statistically significant order effects and cases individual-subject-bias, tests were conducted to determine the potential impact of price-cues on sighted scores across bands of relative expertise and gender.

\section{Preliminary analysis}

Analysing the (Spearman) correlation matrix of the entire dataset's described variables (see Table 2 ), a strong positive correlation is observed $(0,36)(p=0.00)$ between the blind and sighted ratings. 
Table 1: Descriptive statistics

\begin{tabular}{|c|c|c|c|c|c|c|}
\hline & Blind tasting & Sighted tasting & $\begin{array}{l}\text { Price of coffee } \\
\text { per } 200 \mathrm{~g} \text {. }\end{array}$ & Age & $\begin{array}{l}\text { Coffee tastings } \\
\text { per week }\end{array}$ & $\begin{array}{l}\text { Years of } \\
\text { Drinking }\end{array}$ \\
\hline Mean & 2,64 & 2,48 & 54,29 & 31,49 & 8,64 & 15,31 \\
\hline Median & 2,5 & 2,50 & 57,00 & 24 & 7 & 10 \\
\hline Mode & 3 & 2,50 & $\mathrm{n} / \mathrm{a}$ & 23 & 7 & 10 \\
\hline Standard Deviation & 1,10 & 1,08 & 24,76 & 13,70 & 5,81 & 12,47 \\
\hline Kurtosis & 2,34 & 2,29 & 1,84 & 2,57 & 3,40 & 3,29 \\
\hline Skewness & $-0,11$ & $-0,15$ & $-0,19$ & 1,03 & 1,04 & 1,21 \\
\hline Range & 5 & 5 & 72 & 45 & 27 & 48,00 \\
\hline Minimum & 0 & 0 & 18,00 & 18 & 1 & 2 \\
\hline Maximum & 5 & 5 & 90,00 & 63 & 28 & 50 \\
\hline Count & 700 & 700 & 700 & 700 & 700 & 700 \\
\hline
\end{tabular}

Total participants: 100: 55 males, 45 females, 17 experts, 83, non-experts. Prices in ZA Rands.

Table 2: A correlation matrix depicting variables across the entire dataset $(n=700)$

\begin{tabular}{|c|c|c|c|c|c|c|c|}
\hline & & $\begin{array}{c}\text { Sighted } \\
\text { (Round 2) }\end{array}$ & $\begin{array}{c}\text { Blind } \\
\text { (Round 1) }\end{array}$ & Price & $\begin{array}{c}\text { Years of } \\
\text { Drinking }\end{array}$ & $\begin{array}{c}\text { Tastings per } \\
\text { week }\end{array}$ & Age \\
\hline $\begin{array}{l}\text { Sighted } \\
\text { (Round 2) }\end{array}$ & $\begin{array}{l}\text { Correlation } \\
\text { Coefficient }\end{array}$ & 1 & & & & & \\
\hline \multirow[t]{2}{*}{$\begin{array}{c}\text { Blind } \\
\text { (Round 1) } \\
\end{array}$} & $\begin{array}{l}\text { Correlation } \\
\text { Coefficient }\end{array}$ & $0,36 * *$ & 1 & & & & \\
\hline & Sig. (2-tailed) & 0,00 & & & & & \\
\hline \multirow[t]{2}{*}{ Price } & $\begin{array}{l}\text { Correlation } \\
\text { Coefficient } \\
\end{array}$ & $0,14 * *$ & $0,13 * *$ & 1 & & & \\
\hline & Sig. (2-tailed) & 0,00 & 0,00 & & & & \\
\hline \multirow[t]{2}{*}{$\begin{array}{c}\text { Years of } \\
\text { Drinking }\end{array}$} & $\begin{array}{l}\text { Correlation } \\
\text { Coefficient }\end{array}$ & 0,03 & $-0,02$ & 0,00 & 1 & & \\
\hline & Sig. (2-tailed) & 0,42 & 0,45 & 1,00 & & & \\
\hline \multirow[t]{2}{*}{$\begin{array}{c}\text { Tastings per } \\
\text { week } \\
\end{array}$} & $\begin{array}{l}\text { Correlation } \\
\text { Coefficient }\end{array}$ & $\mathbf{0 , 0 8 *}$ & $-0,00$ & 0,00 & $0,14 * *$ & 1 & \\
\hline & Sig. (2-tailed) & 0,03 & 0,94 & 1,00 & 0,00 & & \\
\hline \multirow[t]{2}{*}{ Age } & $\begin{array}{l}\text { Correlation } \\
\text { Coefficient } \\
\end{array}$ & $-0,00$ & $-0,05$ & 0,00 & $0,72 * *$ & $\mathbf{0 , 0 7 *}$ & 1 \\
\hline & Sig. (2-tailed) & 0,90 & 0,13 & 1,00 & 0,00 & 0,03 & \\
\hline
\end{tabular}

* Correlation is significant at the 0,05 level (2-tailed). **: Correlation is significant at the 0,01 level (2-tailed).

The all-important price-to-sighted correlation is positive and medium-to-weak: 0,14 ( $p=0,00)$, suggesting, without controls, that price might perhaps play an intervening role in sighted assessments. The remaining correlations against the sighted variable are all weak and, but for the correlation against tastings per week $(0,08, p=0,03)$, also all insignificant. Additionally, it should be noted that the correlation between blind scores and price $(0,13, p=0,00)$ is also medium-to-weak. From this we can infer the possibility for these two variables to contribute explanatory power to sighted scores without the possibility of multi-colinearity.

Proceeding from the descriptive statistics presented above, a set of appropriately specified OLS regressions is computed to explain sighted tastings across a span of experiential and gender segmentations. The first of these analyses seeks to test for the statistical significance of the price-coefficients contributing to sighted scores within the entire dataset $(n=7$ $\mathrm{x} 100=700$ ) with no experiential or gender controls in place - see equation 1. Those that follow aim to do so with these controls in place, focussing firstly on expertise (experts $=17$, non-experts $=83)$, then gender $($ males $=55$, females $=45)$, then both (male experts $=9$, female experts $=8$, male nonexperts $=46$, female non-experts $=37$ ) - see equations 2 to 4 .
Two points of clarification should be made here. (1) In unreported stepwise regression pre-tests aimed to identify extraneous outlier effects, through use of dummy coding, all 100 subjects were screened for statistically significant (hence consistent) levels of sighted bias, ceteris paribus. Only those subjects consequently identified were included in the final list of candidate variables assessed in the four OLS models that follow. Additional unreported tests conducted to assess the marginal contribution of the remaining non-significant levels of subject bias indicated no material contribution that would alter the findings reported here. (2) Simultaneously, in the self-same battery of step-wise pre-tests, instances of possible serving order bias were also tested for, and where identified, introduced as controls in the four OLS models that follow. So doing, in all of the four models, statistically significant subject and serving order effects are thus fitted, controlled for and thus effectively neutered.

Accordingly, the specification for the first model is follows:

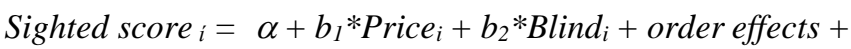
subject effects $+\varepsilon_{i}$ 
where:

$\alpha=$ the estimated intercept term for the sighted regression, $b_{1}$, and $b_{2}=$ the perceived marginal effects of price and blind scores, respectively, and

$\varepsilon=$ a random residual error terms following classic assumptions.

The models that follow aim to assess experiential and / or gender variations within the meta-sample by comparing the absolute value of the slope of each experiential and or gender coefficient relative to each other. This meta-sample analysis allows for the statistical control of differing segment sample sizes; a test that is not possible when isolated segments are regressed independently and then subsequently compared.

The second model specification for the two expertise bands: non-expert and expert reads thus:

$$
\begin{aligned}
{\text { Sighted } \text { score }_{i}=} & \alpha+b_{1} * \text { Price }_{i}+b_{2} * \text { Blind }_{i}+b_{3} D_{N E} * \text { Price }_{i} \\
& +b_{4} D_{N E} * \text { Blind }_{i}+\text { order effects } \\
& + \text { subject effects }+\varepsilon_{i}
\end{aligned}
$$

where:

$D_{N E}=1$ if Non-Expert, 0 if otherwise.

$b_{1}$ and $b_{2}$ as previously defined: now expressing the relationship for Experts, serving as the base-case where $D_{N E}$ $=0$.

$b_{3}$ and $b_{4}=$ the perceived marginal effects of price and blind scores on Non-Experts.

The third model specification for the gender bands: male and female is thus:

$$
\begin{aligned}
\text { Sighted score }_{i}= & \alpha+b_{1} * \text { Price }_{i}+b_{2} * \text { Blind }_{i}+b_{3} D_{F} * \text { Price }_{i} \\
& +b_{4} D_{F} * \text { Blind }_{i}+\text { order effects } \\
& + \text { subject effects }+\varepsilon_{i}
\end{aligned}
$$

where:

$D_{F}=1$ if Female, 0 if otherwise.

$b_{1}$ and $b_{2}$ as previously defined: now expressing the relationship for Males, serving as the base-case where $D_{F}=0$. $b_{3}$ and $b_{4}=$ the perceived marginal effects of price and blind scores for Females.

The fourth and final model specification for males and females within the two expertise bands: non-expert and expert is as follows:

$$
\begin{aligned}
{\text { Sighted } \text { score }_{i}=} & \alpha+b_{1} * \text { Price }_{i}+b_{2} D_{N E} * D_{M} * \text { Price }_{i} \\
& +b_{3} D_{N E} * D_{F} * \text { Price }_{i}+b_{4} D_{E} * D_{F} * \text { Price }_{i} \\
& +b_{5} * \text { Blind }_{i}+b_{6} D_{N E} * D_{M} * \text { Blind }_{i} \\
& +b_{7} D_{N E} D_{F} * D_{\text {Bind }}+b_{8} D_{E} * D_{F} * \text { Blind } \\
& + \text { order effects }+ \text { subject effects }+\varepsilon_{i}
\end{aligned}
$$

where:

$D_{E}=1$ if Expert, 0 if otherwise.

$D_{M}=1$ if Male, 0 if otherwise.

$b_{I}$ as previously defined: now expressing the perceived marginal effect of price for Expert Males, serving as the basecase where both $D_{N E}=0=D_{F}$.

$b_{2}, b_{3}, b_{4}=$ the perceived marginal effects of price on NonExpert Males, Non-Expert Females and Expert Females, respectively.

$b_{5}=$ the perceived marginal effect of intrinsic merit (blind scores) for Expert Males, serving as the base-case where both $D_{N E}=0=D_{F}$.

$b_{6}, b_{7}, b_{8}=$ the perceived marginal effects of intrinsic merit (blind scores) on Non-Expert Males, Non-Expert Females and Expert Females, respectively.

With respect to the above therefore, for the base-case of expert males, coefficients $b_{1}$ and $b_{5}$ represent the marginal effects of price and intrinsic merit within the sighted model. The results of the four models developed are depicted in Table 3 below. 
Table 3: OLS regressions explaining sighted assessments described in equations 1 to 4



2. Sighted: model further incorporating expert bands: $A d j R^{2}: 21,95 \%, F: 9,55(p=0,0000)-n=100 x 7=700$. Equ. 2 .

Constant: 1,75 (14,92).

Blind rating: $0,20(3,18)$.

Additional blind-rating: Non-expert: $0,03(0,50)$. Note: significant only at the $38 \%$ confidence level.

Price rating: 0,0069 (2,45).

Additional price-rating: Non-expert: $-0,0042(-1,42)$. Note: significant only at the $84 \%$ confidence level.

Order Control (x 1): order 3: $-0,44(-4,23)$.

Subject controls (x17): Sbj. 90: -1,19 (-3,30), Sbj. 27: 1,10 (3,02), Sbj. 15: 0,98 (2,71), Sbj. 30: 1,05 (2,65), Sbj. 79: 0,92 (2,54),

Sbj. 97: -0,87 (-2,42), Sbj. 57: -0,86 (-2,37), Sbj. 52: -0,86 (-2,31), Sbj. 88: -0,83 (-2,29), Sbj. 14: -0,85 (-2,24), Sbj. 95: 0,85 (2,23),

Sbj. 9: 0,81 (2,23), Sbj. 20: 0,79 (2,18), Sbj. 23: -0,77 (-2,12), Sbj. 12: -0,76 (-2,09), Sbj. 38: 0,75 (2,06), Sbj. $58:-0,72$ (-1,99).

3. Sighted: model incorporating gender bands: $\operatorname{Adj} R^{2}: 22,15 \%, F: 9,64(p=0,0000), n=100 x 7=700$. Equ.3.

Constant: 1,74 (14,90).

Blind rating: 0,19 (4,96).

Additional blind-rating: Females: 0,09 $(1,95)$. Note: significant at the $95 \%$ confidence level.

Price rating: 0,0057 (3,18).

Additional price-rating: Females: $-0,0049(-2,14)$.

Order Control (x 1): order 3: $-0,44(-4,24)$.

Subject controls (x18): Sbj. 90: -1,18 (-3,25), Sbj. 30: 1,06 (2,87), Sbj. 27: 1,04 (2,83), Sbj. 15: 0,98 (2,70), Sbj. 95: 0,97 (2,67),

Sbj. 79: 0,89 (2,45), Sbj. 57: -0,89 (-2,44), Sbj. 97: -0,86 (-2,36), Sbj. 88: -0,84 (-2,32), Sbj. 20: 0,80 (2,19), Sbj. 68: 0,77 (2,11),

Sbj. 14: -0,77 (-2,10), Sbj. 52: -0,76 (-2,08), Sbj. 23: -0,75 (-2,08), Sbj. 58: -0,74 (-2.03), Sbj, 38: 0.74 (2,03), Sbj. 12: -0,74 (-2,03),

Sbj. 9: 0,75 (2,02).

4. Sighted: model incorporating inter-spliced expertise and gender bands: Adj $R^{2}: 22,00 \%, F: 8,30(p=0,0000), n=100 x 7=700$

Equ.4.

Constant: $1,74(14,83)$

Blind rating: $0,15(1,66)$. Note: significant only at the $91 \%$ confidence level.

Additional blind-rating: Non-expert male: $0,05(0,56)$. Note: significant only at the $42 \%$ confidence level.

Additional blind-rating: Non-expert female: $0,13(1,42)$. Note: significant only at the $84 \%$ confidence level.

Additional blind-rating: Expert female: $0,12(1,00)$. Note: significant only at the $68 \%$ confidence level.

Price-effect: 0,0094 (2,60).

Additional price-coefficient: Non-expert male: $-0,0045(-1,17)$. Note: significant only at the $76 \%$ confidence level.

Additional price-coefficient: Non-expert female: $-0,0091(-2,31)$.

Additional price-coefficient: Expert female: $-0,0058(-1,08)$. Note: significant only at the $72 \%$ confidence level.

Order Control (x 1): order 3: $-0,43(-4,21)$.

Subject control (x 16): Sbj. 90: -1,16 (-3,17), Sbj. 27: 1,06 (2,88), Sbj. 15: 0,99 (2,72), Sbj. 79: 0,90 (2,49), Sbj. 57 : -0,87 (-2,36),

Sbj. 30: 0,96 (2,29), Sbj. 97: -0,83 (-2,27), Sbj. 20: 0,82 (2,26), Sbj. 14: -0,88 (-2,24), Sbj. 88: -0,82 (-2,24), Sbj. 95: 0,90 (2,21),

Sbj. 52: $-0,85$ (-2,17), Sbj. 9: 0,77 (2,07), Sbj. 38: 0,75 (2,06), Sbj. 12: -0,74 (-2,02), Sbj. 23: -0,73 (-1,99).

Note: all variables statistically significant at the $5 \%$ level, unless otherwise indicated. All variable coefficients are presented by order of the absolute value of their associated t-statistic which appears in parenthesis. Sighted rating: mean: $2,40(t=50,71$, estimated with subject and order controls).

\section{Findings}

\section{Sighted meta-model}

The meta-model computed for sighted scores is featured below with a residual error term $(\varepsilon)$ and underpinning $\mathrm{t}$ statistics.

$$
\begin{aligned}
& \text { Sighted score } i=1,74+0,23 \text { Blind rating } i+0,0035 \text { Price }_{i}+t \\
& \text { score: } \quad(14,90)(7,23) \quad(2,37) \\
& 1 \text { order effect }+19 \text { subject effects }+\varepsilon_{i}
\end{aligned}
$$

From the equation above observe that for each "blind" star of intrinsic merit the sighted score is shown to increase by approximately one quarter of a star. Thus the marginal contribution of four blind stars would be a full sighted star.

The second significant variable is price, presenting with a coefficient of $0,0035(\mathrm{t}=2,37)$. For a R75 increase in price, this translates into slightly more than a quarter of a star increase in the sighted score, the same effect as for four blind stars. Additionally note that out of the 100 subjects sampled, 19 present with statistically significant levels of bias. One order effect is also noted: that being the third coffee served, 
where ratings were consistently 0.44 stars less than ratings accorded to the remaining six coffees served. This serving order effect is observed across all four models. With respect to levels of subject bias, this cross-model effect is however more nuanced, where, of the 19 subject statistically significant effects observed here, only 17, 18 and 16 of these appear as significant in models 2, 3 and 4, respectively. Full details are presented in Table 3.

\section{Sighted model of relative expertise}

As per Table 3 the study used sighted assessments to interrogate how segmentations of relative expertise (nonexperts $(n=83)$ versus experts $(n=17))$ respond to price information. Analysed across the same dataset so as to control with differing samples sizes, the price coefficients across these two strata convey a useful perspective on how heuristic errors aggregate between degrees of expertise.

$$
\begin{aligned}
\text { Sighted } \text { score } i=_{i}= & 1,75+0,0069 * \text { Price }_{i}-0,0042 * D_{N E} * \text { Price }_{i} \\
& (14,92)(2,45) \quad(-1,42) \\
& +0,20 * \text { Blind }_{i}+0,03 * D_{N E} * \text { Blind }_{i} \\
& (3,18) \quad(0,50) \\
+ & 1 \text { order effect }+17 \text { subject effects }+\varepsilon_{I}
\end{aligned}
$$

The price coefficient for experts, which serves as the base case in this model, is $0,0069(\mathrm{t}=2,45)$, adding half-a-star for each R75 increment $(0,0069 \times 75=0,52)$. The non-expert price coefficient is $-0,0042(\mathrm{t}=-1,42)$; deducting one-third of a star $(-0,0048 \times 75=0,36)$ for this segment. For experts, blind-based merit presents with a significant intrinsic coefficient of $0,20(\mathrm{t}=3,18)$. For non-experts an additional 0,03 blind stars $(t=0,50)$ is added. Note here that the difference is marginal and not significant. From Table 3 observe that 17 individual instances of subjective bias are notified along with one order effect.

\section{Sighted gender model}

Below follows the sighted model for male and female strata, as reported in Table 3 .

$$
\begin{array}{ll}
\text { Sighted } \text { score }_{i}= & 1,74+0,0057 * \text { Price }_{i}+0,19 * \text { Blind }_{i}- \\
t \text { score: } & (14,90)(3,18) \quad(4,96) \\
& 0,0049 * D_{F} * \text { Price }_{i}+0,09 * D_{F} * \text { Blind }_{i} \\
& (-2,14) \\
& +1 \text { order effect }+18 \text { subject effects }+\varepsilon
\end{array}
$$

In this gender model, the price coefficient for the metasample is $0,0057(\mathrm{t}=2,96)$ effectively adding almost half-astar for every R75 increment $(0,0057$ x $75=0,43)$. This is the base case and represents the price effect on males. Additionally we note a price coefficient of $-0,0049(t=-2,14)$ for women; effectively deducting one third of a star for each R75 increment.

Blind-based price effects are also noted. The blind coefficient for the meta-sample is $0,19(\mathrm{t}=4,96)$; this base case applying to males. The female segment presents with an additionally significant effect of $0,09(\mathrm{t}=1,95)$. Thus the nett contribution of three blind stars would be slightly more than half a star for males $(0,19 \times 3$ blind stars $=0,57)$ and almost a full star for females $(0,28 \times 3$ blind stars $=0,84)$. The same single order effect is noted along with 18 cases of significant subject bias.

\section{Sighted model incorporating inter-spliced expertise and gender bands}

As per equation 4 below, the study analysed how the effects of expertise play out across segmentations of gender.

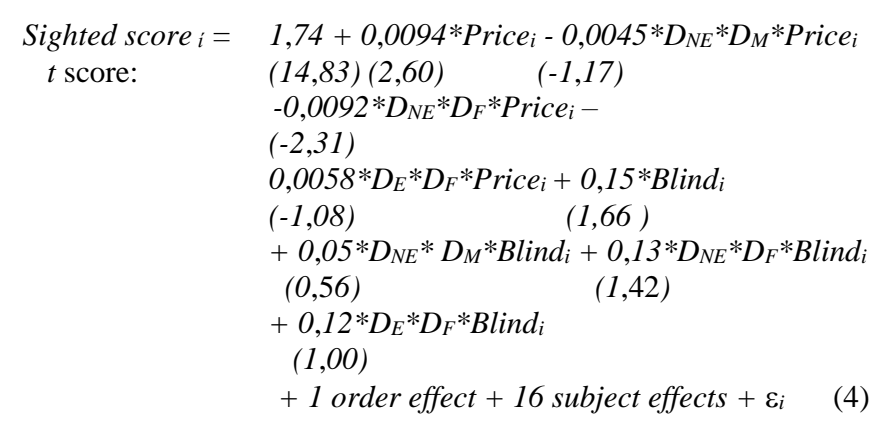

The price coefficient representing the "male expert" base case is $0,0094(\mathrm{t}=2,60)$. This adds almost three-quarters of a star for every R75 increment $(0,0094 \times 75=0,70)$ and represents the segmentation most susceptible to price information. By contrast non-expert females are the least influenced, with a decrement of $-0,0091(t=-2,31)$. A R75 increment will shift their sighted score merely $1 / 44^{\text {th }}$ of a $\operatorname{star}(0,0003 \times 75=0,02)$. Non-expert males and expert females fall between these two extremes, presenting with decrements of $-0,0045(\mathrm{t}=-1,17)$ and $-0,0058(\mathrm{t}=-1,08)$, both figures being statistically insignificant.

A similar pattern of scores presents in the output of blind coefficients. For the base case "male expert" the blind coefficient is $0,15(t=1,66)$. This adds almost half a sighted star for every three blind stars $(0,15 \times 3=0,45)$ and represents the segmentation least susceptible to intrinsic merit. By contrast non-expert females (blind coefficient $=0,13, \mathrm{t}=$ 1,42 ) are the most influenced by the blind assessments, adding almost one whole sighted star for every three blind stars $(0,28 \times 3=0,84)$. Both figures are only mildly significant, respectively presenting at the $91 \%$ and $84 \%$ levels of confidence. Again, non-expert males and expert females fall between these outer scores, with non-significant increments of $0,05(\mathrm{t}=0,56)$ and $0,12(\mathrm{t}=1,00)$, respectively. From Table 3 observe finally that 16 individual instances of subjective bias are noted, along with the same order effect.

Thus out of three potential hypotheses, two were proven to be true $\left(\mathrm{H}_{1}\right.$ and $\left.\mathrm{H}_{2}\right)$, and one $\left(\mathrm{H}_{3}\right)$ was not. The relevance and implications of these findings follows below. 
Table 4: Sight-based price and blind coefficients computed across the study models

\begin{tabular}{|c|c|c|c|c|c|c|c|c|c|}
\hline \multirow[t]{2}{*}{$\begin{array}{l}\text { Sighted } \\
\text { model type: }\end{array}$} & \multirow{2}{*}{$\begin{array}{l}\text { General } \\
\text { Model } \\
\text { (Equ. 1) }\end{array}$} & \multicolumn{2}{|c|}{$\begin{array}{l}\text { Relative Expertise } \\
\text { (Equ. 2) }\end{array}$} & \multicolumn{2}{|c|}{ Gender (Equ. 3) } & \multicolumn{4}{|c|}{ Blended Gender and Expertise (Equ. 4) } \\
\hline & & $\begin{array}{l}\text { Non- } \\
\text { Expert }\end{array}$ & $\begin{array}{l}\text { Expert } \\
\text { (base } \\
\text { case) }\end{array}$ & Female & $\begin{array}{l}\text { Male } \\
\text { (base } \\
\text { case) }\end{array}$ & $\begin{array}{l}\text { Female } \\
\text { Non- } \\
\text { Expert }\end{array}$ & $\begin{array}{l}\text { Female } \\
\text { Expert }\end{array}$ & $\begin{array}{l}\text { Male } \\
\text { Non- } \\
\text { Expert }\end{array}$ & $\begin{array}{l}\text { Male } \\
\text { Expert } \\
\text { (Base } \\
\text { case) }\end{array}$ \\
\hline $\begin{array}{c}\text { price } \\
\text { coefficient }\end{array}$ & $0,0035^{*}$ & $\begin{array}{l}-0,0042 \\
=0,0027\end{array}$ & $0,0069 *$ & $\begin{array}{l}-0,0049^{*} \\
=0,0008\end{array}$ & $0,0057 * *$ & $\begin{array}{l}-0,0092 * \\
=0,0002\end{array}$ & $\begin{array}{l}-0,0058 \\
=0,0036\end{array}$ & $\begin{array}{l}-0,0045 \\
=0,0049\end{array}$ & $0,0094 * *$ \\
\hline$t$-stat & 2,37 & $-1,42$ & 2,45 & $-2,14$ & 3,18 & $-2,31$ & $-1,08$ & $-1,17$ & 2,60 \\
\hline $\begin{array}{l}\text { Standard } \\
\text { error }\end{array}$ & 0,0015 & 0,0029 & 0,0028 & 0,0023 & 0,0018 & 0,0039 & 0,0054 & 0,0038 & 0,0036 \\
\hline $\begin{array}{c}\text { Blind } \\
\text { coefficient }\end{array}$ & $0,23 * *$ & $\begin{array}{l}+0,03 \\
=0,23\end{array}$ & $0,20 * *$ & $\begin{array}{l}+0,09 \\
=0,28\end{array}$ & $0,19 * *$ & $\begin{array}{l}+0,13 \\
=0,28\end{array}$ & $\begin{array}{l}+0,12 \\
=0,27\end{array}$ & $\begin{array}{l}+0,05 \\
=0,20\end{array}$ & 0,15 \\
\hline$t$-stat & 7,23 & 0,50 & 3,18 & 1,95 & 4,96 & 1,42 & 1,00 & 1,66 & 1,66 \\
\hline $\begin{array}{l}\text { Standard } \\
\text { error }\end{array}$ & 0,0314 & 0,0656 & 0,0636 & 0,0483 & 0,0374 & 0,0952 & 0,1220 & 0,0932 & 0,0889 \\
\hline
\end{tabular}

Across the segmentation spans depicted observe how price-coefficients strengthen with relative expertise, and from female to male, while the contribution of (blind) intrinsic quality weakens comparatively.

Note: *: Coefficient is significant at the 0,05 level (2-tailed).

$* *$ : Correlation is significant at the 0,01 level (2-tailed).

\section{Discussion and conclusion}

With respect to the presented models, as well as the summation table of sighted price-cue-coefficients depicted in Table 4, a number of observations are appropriate.

1. Four factors are identified explaining sighted scores: (1) intrinsic merit (referring to blind scores), (2) priceeffects, (3) order effects and (4) subject bias.

2. Within the main model of equation 1 , bind based assessments proved to be the statistically strongest variable explaining sighted merit. This finding suggests that consumers do account for intrinsic merit when assessing the experienced pleasantness of a coffee.

3. The above notwithstanding, these results also demonstrate the extent to which pricing-effects present variously both within the meta-model $\left(\mathrm{H}_{1}\right)$ and also across certain user-profiles, offering detail to how their effect is strengthened within in (1) male and (2) more experienced consumers.

4. In the model developed for experts and non-experts, degrees of pricing affect appear to correlate with degrees of experience, with cue-coefficients increasing from the non-expert model figure of $0,0027(\mathrm{t}=-1,42)$ to the expert model figure of $0,0069(\mathrm{t}=2,45)\left(\mathrm{H}_{2}\right)$. Such findings on coffee confirm the wine-based view by Priilaid et al. (2013), that older, self confessed tasting experts are biased in their sighted assessments, and in the presence of cues such as price, cannot objectively discern the true quality of product. Priilaid et al. (2013) proposed that these forms of judgment could be better done by younger non-experts, and our findings support this view. It is likely that the association between priceeffects and degrees of experience applies across a wider variety of hedonic products (Ariely \& Norton (2009)).

5. With respect to gender, the results of this experiment suggest that male subjects are significantly affected by price information (price coefficient $0,0057, \mathrm{t}=3,18$ ), while females $(-0,0049, \mathrm{t}=-2,14$, with a nett effect of $0,0008)$, are not. The $\mathrm{H}_{3}$ conjecture is thus proven false; the 0,0008 female price coefficient being one the weakest computed here. This finding runs contrary to earlier studies by Almenberg and Dreber (2011), and Priilaid et al. (2013), suggesting that gender effects are likely to vary depending on the product class (conspicuous or otherwise), and possibly price range.

6. In the final model computed across the overlapping subsets of gender and expertise, price affect appears most acute in male experts where a price coefficient of 0,0094 $(t=2,60)$ yields an additional three-quarters of a star for per R75 price increment. At the other extreme, with a price coefficient of $-0,0091(\mathrm{t}=-2,31)$, non-expert females seem the least persuaded by price information, the effective price coefficient computed at a marginal 0,0003 , adding just $2 \%$ of a sighted star.

In summary this study explores the issue of how, with increasing levels of age and experience, System 1-type cognitive judgements become progressively influenced by price information. A degree of price receptivity appears to be built into these sight-based systems of judgment revealing increasing levels of systemic error, or bias. This seems especially so within male coffee drinkers, a finding that, as it applies to the coffee category in particular, constitutes a unique contribution to the literature.

More broadly, as illustrated in Figure 1 below, we demonstrate how, with increasing experience, sighted assessments appear to collect price information via pricedriven interpretations of quality with a commensurate and progressive neglect of the potential contribution of any intrinsic merit. 


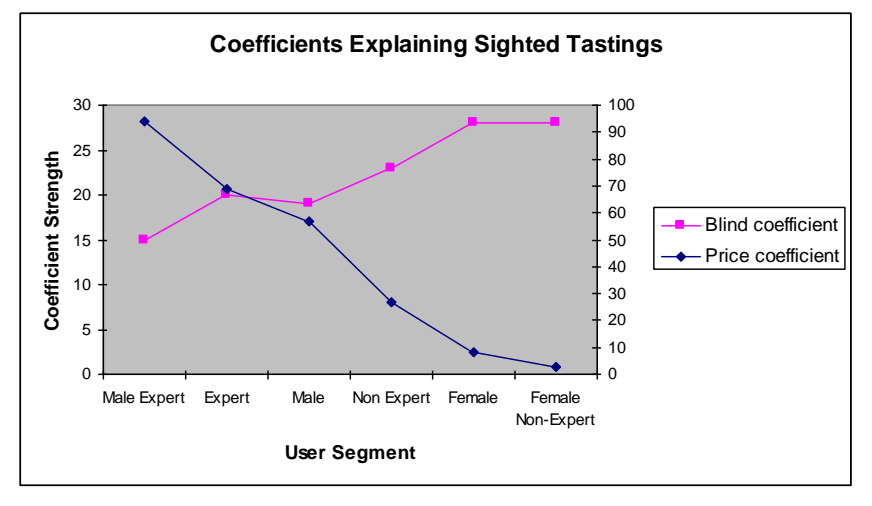

Observe how, with expertise, price coefficients (calibrated on the right hand) increase in strength while blind coefficients (calibrated on the left) weaken simultaneously.

\section{Figure 1: Coefficients explaining sighted tastings across user segments}

\section{Managerial implications}

This work extends our understanding of how coffee consumers respond to price information and suggests that marketers of coffee and related products aim their extrinsic cues towards older more experienced coffee drinkers, particularly males. The implied narrowing of the marketing focus would in turn propose a more specified and costeffective approach to price-strategy actions, in particular the development of more strategic budgets as they relate to advertising and promotion.

Price, as it is shown, has a particular hedonic message, with the message changing in intensity depending on levels of experience and gender. The tone, style and manner of advertorials should be adjusted accordingly. The implications of this cue-based style of segmentation fits within the context of work by Venkatraman, et al. (2012) which identifies segmentation as one of the central aims for marketers. Effective segmentation; that is the division of a product's consumers into unique and relevant subsets, typically incorporates data related to demographics, geographic position, and purchase habits. More recently though, as Venkatraman, et al. (2012, p. 143) point out, "research into cognitive and affective processes underlying consumption decisions shows that these variables can improve the matching of consumers with products beyond traditional demographic and benefit approaches" Our research does just this. Using the pricing of coffee by way of example, we posit that neuro-marketing investigations of this type offer a cheap and effective means to better connect the way consumers think about products to more conventional sources of market data.

Price cues notwithstanding, our results also suggest that intrinsic merit remains a significant component in the enjoyment of coffee. Further investigation into what intrinsic qualities are especially appreciated by coffee drinkers will be necessary in order for brands to enhance or adapt to user preference. This will prove an important source of future differentiation.

\section{Limitations and Future Research Direction}

The findings of this study are subject to certain limitations. Because of the developing nature of neuro-marketing research, there is limited experimentally driven theory and little consensus as to how exactly humans respond to cues such as price. In the absence of corroborating research the application of such findings to the broader population should be avoided. The paucity of literature on cue-based research imposes limitations on the accuracy of measurement and even acceptance of the price-error construct. In time, an improved understanding of price-errors will allow for the development of better calibrations and treatment procedures. Ultimately this will generate more consistent results and definitive conclusions.

With respect to the user-segmentations under analysis, we are aware that the size of certain sub-samples was limited. Assessments done by expert males numbered 63 (7 x 9), and expert females 56 ( $7 \times 8)$. The statistical validity of our findings is nonetheless reflected in the governing $t$-statistics, and justified by the robust total-sample analysis conducted across the pre-specified segmentations of gender and expertise (as opposed to a segment-by-segment analysis). As stated earlier, this form of testing controls for different sample sizes. This notwithstanding, the findings of this paper should be treated with caution until corroborating studies are published.

A further study limitation was noted in respect to the numerous ways in which coffee can be consumed. By comparison to wine, coffee has more additive substances that may be added to it so as to change its intrinsic quality. For example one may add milk, sugar and change the temperature of the water. In future coffee-related research it is recommended that the experimenter include questions on how respondents generally enjoy their coffee, including specifics as to the levels of milk and sugar they typically prefer. Such factors may be employed as controls with respect to those, who, for example, prefer their coffee black with no sugar.

Further research is also required to classify and quantify the degree to which gender and expertise bands respond to price information across other product classes and cue-types. Certainly, gender effects may vary depending on product class, and possibly price range. Additional studies have also demonstrated gender differences in pathologies such as gambling and pornographic addiction (dominated by men) versus eating disorders and compulsive shopping (dominated by women) (Saad, 2013). More so we know little of how different user-segments respond to hedonic-type products like ice-cream, chocolate and cheese, and little of how cues like brands, retailer and area-of-origin are differentially processed with respect to price. As with buying a painting from a Sotheby's auction in London, as opposed to a lesser branded retailer in, say, Cape Town, touch-points within the entire purchase experience are likely to have a particular potency within the mind of the consumer (Thompson, 2012). 
While the price errors noted here are applicable to a suite of low priced coffees, research should be aimed at higher priced products too. More so comparative analysis should be also conducted between products and services as well as between private, business and state-sponsored forms of consumption. Such research would certainly expand our understanding of the price-error effects show-cased here.

\section{References}

Abramson, C.I. 1994. A primer of invertebrate learning: The behavioural perspective. Washington, DC: American Psychological Association.

Almenberg, J. \& Dreber, A. 2011. 'When does the price affect the taste? Results from a wine experiment', Journal of Wine Economics, (6)1: 110-121

Amanzio, M. \& Benedetti, F. 1999. 'Neuropharmacological dissection of placebo analgesia: Expectation-activated opioid systems versus conditioning activated specific subsystems', Journal of Neuroscience, 19: 484-494.

Ariely, D. \& Norton, M.I. 2009. 'Conceptual consumption', Annual Review of Psychology, 60: 475-499.

Berridge, K.C. \& Aldridge, J.W. 2008. 'Decision utility, the brain, and pursuit of hedonic goals', Social Cognitive and Affective Neuroscience, 26: 621-646.

Chao, A. \& Schor, J. 1988. 'Empirical tests of status consumption: Evidence from women's cosmetics', Journal of Economic Psychology, 19(1): 107-131.

Cunha, M. \& Shulman, J. 2010. 'Assimilation and contrast in price evaluations', Journal of Consumer Research, 37, 822-835.

De Houwer, J., Thomas, S. \& Baeyens, F. 2001. 'Associative learning of likes and dislikes: A review of 25 years of research into evaluative conditioning', Psychological Bulletin, 127(6): 853-869.

Dodds, W. B. \& Monroe, K.B. 1985. 'The effect of brand and price information on subjective product evaluations', Advances in Consumer Research, 12: 85-90.

Dollard, J. \& Miller, N.E. 1950. Personality and psychotherapy. New York, NY: McGraw-Hill.

Epstein, S. 2010. 'Demystifying intuition: What it is, what it does, and how it does it', Psychological Enquiry, 21: 295-312.

Erikson, G. \& Johansson, J. 1985. 'The role of price in multiattribute product evaluations', Journal of Consumer Research, 12: 195-199.

Evans, J.S.B.T. 2008. 'Dual-processing accounts of reasoning, judgement, and social cognition', Annual Review of Psychology, 59: 255-278.

Gerstner, E. 1985. 'Do higher prices signal higher quality?', Journal of Marketing Research, 22(May): 209-215.

Goldstein, R., Almenberg, J., Dreber, A., Emerson, J.W., Herschkowitsch, A. \& Katz, J. 2008. 'Do more expensive wines taste better? Evidence from a large sample of blind tastings', Journal of Wine Economics, 3: 1-9.
Hogarth, R.M. 2001. Educating intuition. Chicago, Il: University of Chicago Press.

Hoppert, K., Mai, R., Zahn, S., Hoffmann, S. \& Rohm, H. 2012. 'Integrating sensory evaluation in adaptive conjoint analysis to elaborate the conflicting influence of intrinsic and extrinsic attributes', Appetite, 59: 949-955.

Hull, C.L. 1943. Principles of behaviour. New York, NY: AppletonCentury-Crofts.

Kahneman, D. 2003. 'A perspective on judgement and choice. Mapping bounded reality', American Psychologist, 58: 697-720.

Kahneman, D. 2012. Thinking, fast and slow. London: Penguin Books.

Kahneman, D., Slovic, P. \& Tversky, A. 1982. Judgement under uncertainty. Cambridge, M.A: Cambridge University Press.

Leavitt, H.J. 1954. 'A note on some experimental findings about the meaning of price', Journal of Business, 27(July): 205-210.

Lee, L., Frederick, S. \& Ariely, D. 2006. 'Try it, you'll like it - The influence of expectation, consumption and revelation on preferences for beer', Psychological Science, 17(12): 1054-1058.

Lee, N., Broderick, A.J. \& Chamberlain, L. 2007, 'What is 'neuromarketing'? A discussion and agenda for future research', International Journal of Psychophysiology, 64, 199-204.

Lens, I., Driesman, K., Pandelaere, M., \& Janssens, K. 2012. 'Would male consumption capture the female eye? Menstrual cycle effects on women's attention to status products', Journal of Experimental Social Psychology, 48: 346-349.

Lichtenstein, D. \& Burton, S. 1989. 'The relationship between perceived and objective price-quality', Journal of Marketing Research, 26: 429-443.

Malhotra, N. K. 2010. Marketing research: An applied orientation. $6^{\text {th }}$ Edition. Upper Saddle River, NJ: Pearson Education International.

McClure, S.M., Li, J., Tomlin, D. Cypert, K.S., Montague, K.M. \& Montague, P.R. 2004. 'Neural correlates of behavioural preference for culturally familiar drinks', Neuron 44: 379-387.

Meyers, D. G. 2002. Intuition, its powers and perils. New Haven, CT: Yale University Press.

Meyers-Levy, J. \& Maheswaran, D. 1991. 'Exploring differences in males' and females' processing strategies', Journal of Consumer Research, 19: 63-70.

Meyers-Levy, J. \& Sternthal, B. 1991. 'Gender differences in the use of message cues and judgements', Journal of Marketing Research, 28: 84-96.

Montague, R. 2006. Why choose this book?: How we make decisions. New York: Dutton Press.

Morewedge, C., \& Kahneman, D. 2010. 'Associative processes in intuitive judgement', Trends in Cognitive Sciences, 10: 435-440. 
Nisbett, R. \& Ross, L. 1980. Human inference: Strategies and shortcomings of social judgement. Eaglewood Cliffs, NJ: PrenticeHall.

Olsen, J.C. 1977. 'Price as an informational cue: Effects on product evaluations'. In Woodside, A.G. (Ed.) Consumer and industrial buying behaviour. New York, NY: North Holland, pp. 267-286.

Pecotich, A. \& Ward, S. 2010. 'Taste testing of wine by expert and novice consumers in the presence of variations in quality, brand and country of origin cues', AAWE Working Paper, 66: 1-55.

Petty, R.E. \& Wegener, D.T. 1999. 'The elaboration-likelihood model: Current status and controversies', In Chaiken, S. \& Trobe, Y. (Eds.), Dual-process theories in social psychology. New York: Guilford, pp. 41-72.

Plassmann, H., O'Doherty, J., Shiv, B. \& Rangel, A. 2008. 'Marketing actions can modulate neural representations of experienced pleasantness', Proceedings of the National Academy of Sciences, 105: 1050-1054.

Plassmann, H., Ramsøy, T.Z., \& Milosavljevic, M. 2012. 'Branding the brain: A critical review and outlook', Journal of Consumer Psychology, 22: 18-36.

Priilaid, D. 2006. 'Wine's placebo effect: How the extrinsic cues of visual assessment mask the intrinsic quality of South African red wine', International Journal of Wine Marketing, 18(1): 17-32.

Priilaid, D. 2007. 'The placebo of place: Terroir effects in the blind and sighted quality assessments of South African varietal wines', Journal of Wine Research, 18(2): 87-105.

Priilaid, D. \& van Rensburg, P. 2016. 'How price-effects accrue with product experience and expertise', Food Quality and Preference, 48 : 166-173.

Priilaid, D., Feinberg, J., Carter, O. \& Ross, G. 2009. 'Follow the leader: How expert ratings mediate consumer assessments of hedonic quality', South African Journal of Business Management, 40(4): $15-22$.

Priilaid, D., Sevenoaks M., Aitken, R., \& Chisholm, C. 2013. 'How price demeans sighted assessments across user profiles', International Journal of Wine Business Research, 25(2), 108-124.

Rao, A.R. 2005. 'The quality of price as a quality cue', Journal of Marketing Research, 42(November): 401-405.

Rao, A.R. \& Monroe, K.B. 1988. 'The moderating effect of prior knowledge on cue utilization in product evaluations', Journal of Consumer Research, 15(September): 253-264.

Rao, A.R. \& Monroe, K.B. 1989. The effect of price, brand name, and store name on buyer's perceptions of product quality: An integrative review, Marketing Science Institute Working Paper Series, Report No. 89-109, Marketing Science Institute, Cambridge, MA 02138.

Rao, A.R. \& Sieben, W.A. 1992. 'The effect of prior knowledge on price acceptability and the type of information examined', Journal of Consumer Research, 19(September): 256-270.

Saad, G. 2013. 'Evolutionary consumption', Journal of Consumer Psychology, 23(3): 351-371.
Saad, G. \& Vongas, J.G. 2009. 'The effect of conspicuous consumption on men's testosterone levels', Organisational Behaviour and Human Decision Processes, 110:80-92.

Shermer, M. 1997. Why people believe weird things. New York, NY: MJF Books.

Shiv, B., Carmon, Z. \& Ariely, D. 2005. 'Placebo effects of marketing actions: Consumers may get what they pay for', Journal of Marketing Research, 42: 383-393.

Siegrist, M. \& Cousin, M. 2009. 'Expectations influence sensory experience in a wine tasting', Appetite, 52: 762-765.

Simon, H.A. 1992. 'What is an explanation of behaviour?', Psychological Science, 3: 150-161.

Smith, E.R. \& DeCoster. J. 2000. 'Dual-process models in social and cognitive psychology: Conceptual integration and links to underlying memory systems', Personality and Social Psychology Review, 4: 108-131.

Solnais, C., Andreau-Perez, J., Sánchez-Fernández, J. \& AndréuAbela, J. 2013. 'The contribution of neuroscience to consumer research: A conceptual framework and empirical review', Journal of Economic Psychology, 36(2013): 68-81.

Stafford, J. \& Enis, B. 1969. 'The price-quality heuristic: An extension', Journal of Marketing Research, 6(4): 456-459.

Stanovich, K.E. \& West, R.F. 2000. 'Individual differences in reasoning: Implications for the rationality debate', Behavioural and Brain Sciences, 23: 645-665.

Strack, F. \& Deutch, R. 2004. 'Reflective and impulsive determinants of social behaviour', Personality and Social Psychology Review, 8: 220-247.

Taleb, N. 2007. The Black Swan. London: Penguin.

Tellis, G.J. \& Wernerfelt, B. 1987. 'Competitive price and quality under asymmetric information', Marketing Science, 6(Summer): $240-53$.

Thompson, D. 2012. The $\$ 12$ million dollar stuffed shark: The curious economics of contemporary art. London: Aurum Press.

Venkatraman, V., Clithero, J.A., Fitzsimons, G.J. \& Huettel, S.A. 2012. 'New scanner data for brand marketers: How neuroscience can help better understand differences in brand preferences', Journal of Consumer Psychology, 22: 143-153.

Zeithaml, V.A. 1988. 'Consumer perceptions of price, quality and value: A means end model and synthesis of evidence', Journal of Marketing, 52(July): 2-22. 